\title{
A Few Methods for Estimating Life Expectancy
}

\author{
M. Phukon, M. I. Ahamed* \\ Department of Statistics, North-Eastern Hill University, Umshyrpi College, Meghalaya, \\ India
}

Received 1 April 2019, accepted in final revised form 29 May 2019

\begin{abstract}
In this paper, firstly, an extensive empirical investigation is done by fitting linear regressions exhaustively to observe the pattern and nature of linear relationships of life expectancies of each age-group with that of all other age-groups in fifty-four Sample Registration System (SRS) life tables of Assam state of India. Secondly, two second degree polynomial regression models have been proposed for estimating life expectancies at birth $\left(e_{0}\right)$. Both the models have been empirically illustrated in fifty-four SRS life tables of India and fifty-four SRS life tables of each of 16 major Indian states. The estimated values of $e_{0}$ are examined in relation to estimated values of the same by some other methods and $e_{0}$ values available in SRS tables of the years 2001-05 and 2011-15. Moreover, $e_{0}$ values for all districts of Assam are estimated by using one of the proposed polynomial regressions together with some indirect techniques of estimation.
\end{abstract}

Keywords: Life Expectancy; Model life table; Mortality rates; Regression; Survivorship function.

(C) 2019 JSR Publications. ISSN: 2070-0237 (Print); 2070-0245 (Online). All rights reserved. doi: http://dx.doi.org/10.3329/jsr.v11i3.40874

J. Sci. Res. 11 (3), 321-338 (2019)

\section{Introduction}

Patterns of human mortality in the form of summary presentation of a cohort population are best expressed in life tables. A life table presents a comprehensive picture of a cohort population that gets depleted systematically through deaths at each age, and thus portrays the process of life itself to facilitate systematic study of phenomenon of survival and death [1].

The rigorous challenge in the construction of model life tables is to obtain generalizations on age pattern of mortality through mathematical functions termed as laws of mortality under appropriate choice of assumptions, which in turn will pave the way for conducting mortality analysis. Moreover, considering age pattern of mortality as empirical, typical patterns are selected as laws of mortality and then models by different levels of mortality are generated within each identified pattern. These life tables are used for smoothing of data, incorporating age-specific mortality patterns, forecasting of

\footnotetext{
Corresponding author: ahamed.irphan@gmail.com
} 
mortality rates, and demographic estimation in circumstances where complete vital registration is not in action [2]. Using Model life tables (MLTs), age-specific mortality rate can be adequately expressed by two or three parameters such as a family to which model belongs and the mortality levels.

First empirical attempt to construct the MLTs was made by Notestein et al. [3]. However, first set of MLTs was published by the United Nations (UN) in 1955 [4]. In 1966, Coale and Demeny proposed a set of MLTs with four different age patterns of mortality (North, South, East and West) corresponding to the level of mortality by plotting the probability of dying against age. And again UN in 1982 came up with a new set of MLTs known as New UN MLTs. A revised version of Coale and Demeny's MLTs were again published in the year 1983 [5]. In this direction of research studies, among a large number of past and ongoing contributions, a few have been pertinently mentioned here, by seeing their specific relevance to our work, as follows.

Kesarwani [6] followed the following procedure to estimate the life expectancy at birth (LEB) using the information on infant mortality rate (IMR).

At first, the regression model of the $\ln (L E B)=\alpha+\beta * I M R$ is used for estimating LEB. Then, in the light of the techniques and procedures used by Gabriel and Ronen [7], Sinha and Gupta [8] and Ponnapalli [9], Kesarwani [6] obtained regression model $\ln (L E(x))=\alpha+\beta * \ln (L E B)$ in which the estimated LEB was used to estimate life expectancies $L E(x)$ for all age groups $x=1,5,10, \ldots, 85+$.

In the first part of our work, based on fifty-four Sample Registration System (SRS)based life tables of Assam, 18 for males, 18 for females and 18 for total of males and females of the period 1995 to 2016, a comprehensive investigation has been done to observe the nature of linear relationships between logarithms of life expectancies of each age group as explanatory variable to the logarithm of life expectancies of all other age groups as response variable by fitting linear regressions one after another exhaustively. From this investigation, a few models that provide best linear regression fits have been selected with the help of the fitted graphs. Moreover, by using the said Kesarwani's [6] method for construction of MLTs, life expectancies of all age groups are estimated based on the same data. In Tables 1-3, the performances of the selected models and Kesarwani's model, in terms of goodness of fits measures, are shown by the coefficients of determination and standard errors separately for male, female and total respectively.

From this empirical study, it has been found that life expectancies at some particular ages other than zero can also be used, rather than using $e_{0}$ and IMR, for estimating life expectancy at any age, such estimates fit better to the SRS life tables. The finding here has shown certain exceptions to some standard techniques popularly used in the construction of MLTs.

LEB is generally considered as the basis for determining mortality levels of different age groups in a population; however, life expectancies at ages other than zero are also used for studying human longevity, in historical populations and most developing countries, the incidence of high rate of infant and early childhood mortality results in lower values of $e_{0}$ than at other ages, and in such populations those surviving the hazards of early childhood 
have a higher life expectancy than new born and the highest life expectancy occurs not at birth but at a later stage [10].

Expressing life expectancy as an exponential function of age and also approximating the logarithm of life expectancy at age $x$ by a quadratic equation of $x$ for the entire range of $x$ except the childhood age interval of less than five years were demonstrated by Mitra [11]. In his study, it was observed that expectation of life assumed its maximum value in the interval (0-4) and that age approached to the age 0 with increase in life expectancy, and the MLTs were used to determine ages of maximum life expectancy and the parameters of the quadratic equation for a number of levels.

In India, the SRS is the most regular source of demographic statistics; it is based on a system of dual recording of births and deaths in fairly representative sample units spread all over the country, SRS estimates are generally valid and reliable for the country as a whole and for bigger states, the sample size of SRS has been increased to allow for estimates by natural divisions within the bigger states, evaluations during 1970s and 1980s show that completeness of recording of births and deaths by the SRS is generally good and errors in recording of events are minimal. However, systematic evaluation of the SRS has not been taken up for quite some time, indirect estimates for 1990s and after suggests that registration completeness has worsened and interstate variations widened, a pluralistic evaluation framework is recommended [12].

In the SRS based life tables of India, till the year 1980, the highest life expectancy remained occurred at age five, and the crossover to age one began from 1981-85. In the UN MLTs for developing countries (South Asian pattern, 1982), the shifting of highest life expectancy from age five to age one occurred in the life tables corresponding to $e_{0}=57.0$ (for males) and $e_{0}=59.0$ (for females). For India's SRS life tables, this crossover of 198185 took place at level when $e_{0}=55.45,53.95,55.67$ for individuals, males, and females, respectively in all major states except Kerala [13].

While inspecting SRS-based life tables of India, it can be observed that the difference between the life expectancies at ages 0 and 1 was such that life expectancy at age one was more than $e_{0}$ by 6.5 years in 1971-75, and the difference had decreased up to 1.86 years in 2012-16. In the life table of 1995-99, $e_{0}$ was less than life expectancies at ages from one to seven and so also, in 1997-01, $e_{0}$ was less than life expectancies at ages from one to six. In 2012-16, $e_{0}$ was less than life expectancies at ages from one to three although in all cases life expectancies began to diminish gradually from age one. Among all the major states of India, Kerala is the only state where the gap between life expectancies at ages 0 and 1 was very less, which was 0.7 year in 1986-90, and the gap reduced to zero in 1995-99 and in 1996-00 crossover happened, i.e., $e_{0}$ became highest and thenceforth continued to be so till date.

While going through the above a few pertinent literatures, it can always be observed that $e_{0}$ is somehow inextricably related to life expectancies at childhood ages. At this juncture, it is relevant to note that, in regard to construction of MLTs using childhood mortality ages, Lederman [14] developed a series of one parameter and two parameters life tables based on regression technique. Then, the author proposed new model life tables by generating the logarithm regression equation between probability of dying at ages $x$ 
and $(x+5)$. He estimated different sets of regression coefficients for each equation based on different independent variables (e.g. $e_{0},{ }_{1} q_{0},{ }_{5} q_{0},{ }_{15} q_{0},{ }_{20} q_{30},{ }_{20} q_{45}$ and $m 50+$ ) or a pair of variables.

From the above facts, it can also be inferred that $e_{0}$ is also inextricably related to mortality conditions in childhood ages. Roy [15] derived reliable estimate of child survivorship functions $l_{x}=1-q_{x}$ for India by logit smoothing. It is justifiable that child survivorship functions strongly influence $e_{0}$.

Keeping this in the background, in the second part of our work, two second degree polynomials have been derived for estimating $e_{0}$. One shows relationship between $e_{0}$ and survivorship functions at early childhood ages (0-2), i.e., $l_{1}$ and $l_{2}$; the other shows between $e_{0}$ and survivorship functions at childhood ages (0-4), i.e., $l_{1}, l_{2}, l_{3}$ and $l_{4}$, where $l_{1}, l_{2}, l_{3}$ and $l_{4}$ are conditional survivorship probabilities at ages one, two, three and four respectively. By fitting polynomial regression models, $e_{0}$ is estimated from SRS-based life tables of India and 16 major Indian states. Thus, two polynomial regression models which are useful in estimating $e_{0}$ are proposed here. Moreover, by using one of the proposed two models, i.e., $e_{O}(\mathrm{t})=\alpha_{1}+\beta_{1} * l_{1}+\varphi_{1} * l_{2}+\eta_{1} * l_{2}^{2}$ as an estimating equation together with the application of Trussell's variant of Brass Method and Weibull survival function in children ever born (CEB), children surviving (CS) of Indian census data of 2001 and 2011 for estimating $l_{1}$ and $l_{2}$ values with logit smoothing $[13,16]$, district level life expectancies of all the districts of Assam have been estimated. The estimated values of $e_{0}$ are presented in Table 7.

\section{Data and Methods}

\subsection{Data}

SRS-based life tables of India published by the office of the Registrar General of India are used in this study. This paper has considered fifty four SRS life tables from 1995-99 to 2012-2016 of Assam, 18 each for males and females, and 18 for the total in the empirical investigation, explained in the introduction part. SRS-based life tables of the same period of India and its sixteen major states, viz., Andhra Pradesh, Assam, Bihar, Gujarat, Haryana, Himachal Pradesh, Karnataka, Kerala, Madhya Pradesh, Maharashtra, Odisha, Punjab, Rajasthan, Tamil Nadu, Uttar Pradesh and West Bengal, separately for both sexes and the total of both sexes are used in fitting the two polynomial regression models proposed in this paper. The two second degree polynomials are used for estimating $e_{0}$. $\mathrm{CEB}, \mathrm{CS}$ and total numbers of women in child bearing ages are taken from Indian Census data of 2001 and 2011 for estimating life expectancies in district levels of Assam.

\subsection{Methods}

\subsubsection{Regression-based model life tables}


In the first part of our work, the following methods are used and procedures are followed as well.

In the equation $\ln (L E(x))=\alpha+\beta^{*} \ln (L E B)$, in place of the $\ln (L E B), \ln (L E(x))$ is used as explanatory variable with a particular value of $x$ (say $x=1$ ) and then the regression $\ln (L E(y))=\alpha+\beta^{*} \ln (L E(x)) \quad x \neq y ; y=1,5,10, \ldots, 85+$ is fitted to estimate life expectancies for all age groups based on $\ln (L E(1))$. In the next step, $\ln (L E(x))$ is used as explanatory variable with $x=5$ and life expectancies for all ages based on $\ln (L E(5))$ are estimated. The process is continued exhaustively for all ages $x$. Besides, by using IMR as independent variable, estimation of life expectancies of all ages $x$ is also done. Thus, a large number of regression equations are set up and every time graph is fitted between estimated life expectancies and corresponding life expectancies from SRS data. The graphs are helpful in identifying best fitting models. Kesarwani's [6] procedure, explained in introduction part, is also illustrated in the same SRS data as a part of the investigation.

\subsubsection{Polynomial regression models}

In this second part of our work, two second degree polynomials have been obtained each of which is giving relationship between $e_{0}$ and survivorship functions at some early childhood ages.

In populations where the highest life expectancy occurs at age one, those who survive the hazards of infancy gains extra years of life expectancy on the top of the year they have already lived. This changes in mortality in the first year of life strongly affect $e_{0}$; with this background, Romo and Becker [10], and Sarma and Choudhury [13] constructed relationships between $e_{0}$ and survivorship probability at age one $\left(l_{1}\right)$ in the form of linear and quadratic equations respectively.

In this paper, from the perspective of the above observation, i.e., changes in mortality in the first year of life strongly affect $e_{0}$ and, at the same time, taking into consideration that child survivorship functions at early ages are inextricably related to $e_{0}$, two second degree polynomials are derived by considering the equations obtained by Romo and Becker [10] and Sarma and Choudhury [13]:

$e_{O}(\mathrm{t})={ }_{1} L_{O}(\mathrm{t})+e_{1}(\mathrm{t}) l_{1}(\mathrm{t})$

$e_{O}=a+(b+c) l_{1}+d l_{1}^{2}$

where ${ }_{1} L_{O}(t)$ is the person-years lived between birth and age one, $e_{1}(t)$ is the life expectancy at age one and $l_{1}(t)$ is the probability of survivorship function at age one.

In the same way, the following equation may be obtained

$e_{0}(t)=\int_{0}^{1} l(\sigma, t) d \sigma+\int_{1}^{2} l(\sigma, t) d \sigma+\int_{2}^{\theta} l(\sigma, t) d \sigma$

where $\theta$ is the highest age attained by a member of population.

Considering the effect of childhood mortality changes in age interval $(0-2)$ on $e_{0}$, the following equation can be obtained:

$e_{O}(t)={ }_{1} L_{O}(t)+{ }_{1} L_{1}(t)+e_{2} * l_{2}(t)$ 
${ }_{1} L_{O}(t)$ is a weighted linear function of $l_{1}(t)$ and so also ${ }_{1} L_{1}(t)$ is a weighted linear function of $l_{1}(t)$ and $l_{2}(t)$. By assuming $e_{2}(t)$ as a linear function of $l_{2}(t)$, the above equation may be expressed as:

$$
\begin{aligned}
& e_{0}=a+b l_{1}+c l_{1}+d l_{2}+\left(u+v l_{2}\right) * l_{2} \\
& \Rightarrow e_{O}(\mathrm{t})=\alpha_{1}+\beta_{1} * l_{1}+\varphi_{1} * l_{2}+\eta_{1} * l_{2}^{2}
\end{aligned}
$$

where, $\alpha_{1}, \beta_{1}, \varphi_{1}, \eta_{1}$ are the four parameters of the second degree polynomial equation.

Proceeding in the same way and also considering the effect of childhood mortality changes in age interval (0-4) on $e_{0}$, the following equation can also be obtained:

$e_{O}(\mathrm{t})=\alpha_{2}+\beta_{2} * l_{1}+\varphi_{2} * l_{2}+\eta_{2} * l_{3}+\kappa * l_{4}+\xi * l_{4}^{2}$

where $\alpha_{2}, \beta_{2}, \varphi_{2}, \eta_{2}, \kappa, \xi$ are the six parameters of the second degree polynomial equation.

Thus, two polynomial regression models (3) and (4) for estimating $e_{0}$ have been obtained.

The models are fitted to the SRS-based life tables for India and 16 Indian states (males, females and the combined) of the specific period mentioned already. The fitted

\begin{tabular}{|c|c|c|c|c|}
\hline \multirow[b]{2}{*}{$\begin{array}{l}\text { States } \\
\text { /India }\end{array}$} & \multirow[b]{2}{*}{ Sex } & \multicolumn{3}{|c|}{ Fitted polynomial regression models } \\
\hline & & Model by (2) & Model by (3) & Model by (4) \\
\hline \multirow{11}{*}{$\begin{array}{l}\text { Andhra } \\
\text { Pradesh }\end{array}$} & \multirow[t]{4}{*}{ Male } & $2600.9-5491.5 l_{1}$ & $-551.2-653.8 l_{1}$ & $-332-5764.21 l_{1}$ \\
\hline & & $+2969.4 l_{1}^{2}$ & $+1935.5 l_{2}-665.9$ & $+34742.11 l_{2}$ \\
\hline & & & $l_{2}^{2}$ & $-58279.7 l_{3}+30116.89$ \\
\hline & & & & $l_{4}-415.33 l_{4}^{2}$ \\
\hline & \multirow[t]{3}{*}{ Female } & $-4887.3+10211.7 l_{1}$ & $-3295.5-51.6 l_{1}$ & $35.7+2658.8 l_{1}-$ \\
\hline & & $-5257.5 l_{1}^{2}$ & $+6969.7 l_{2}-3553.7$ & $11102.2 l_{2}$ \\
\hline & & & $l_{2}^{2}$ & $\begin{array}{c}+1289.3 l_{3}-4519 l_{4} \\
+107.9 l_{4}^{2}\end{array}$ \\
\hline & \multirow{4}{*}{$\begin{array}{c}\text { Total/Pers } \\
\text { on }\end{array}$} & $590.9-1298.8 l_{1}$ & $660.2-472.3 l_{1}$ & $3701.5-927.4 l_{1}$ \\
\hline & & $+785.9 l_{1}^{2}$ & $-885.1 l_{2}+772.3 l_{2}^{2}$ & $+9101.9 l_{2}$ \\
\hline & & & & $-20592.8 l_{3}+4685.0$ \\
\hline & & & & $l_{4}+4115.9 l_{4}^{2}$ \\
\hline & \multirow[t]{3}{*}{ Male } & $1933.7-4183.7 l_{1}$ & $913.6-169.2 l_{1}$ & $879.7+555.1 l_{1}-$ \\
\hline & & $+2331.4 l_{1}^{2}$ & $-1809 l_{2}+1143.3 l_{2}^{2}$ & $3069.5 l_{2}$ \\
\hline & & & & $+3874.7 l_{3}-3220.3 l_{4}$ \\
\hline Assam & Female & & $-11738+103 y$ & $2878+71081$ - \\
\hline Assam & & $-1100+240$ & $-11 / 5.0+10.5 l_{1}$ & $201.07 / 10.0 l_{1}$ \\
\hline
\end{tabular}
polynomials models are given by models (2-4) as follows: 
$-1148.9 l_{1}^{2} \quad+2435.3 l_{2}-1198.1 l_{2}^{2} \quad 2284.3 l_{2}$

$+1867.5 l_{3}-956.4 l_{4}-$ $455.6 l_{4}^{2}$

$\begin{array}{cc}\text { Total/Pers } & 342.5-813.7 l_{1} \\ \text { on } & +548.4 l_{1}^{2}\end{array}$

109.5-141.4 $l_{1}$

$-137.3 l_{2}+247.1 l_{2}^{2}$
874.3-1793.2 $l_{1}$

$+9717.3 l_{2}$

- $15686.7 l_{3}+5883.7$

\begin{tabular}{cccc} 
& & & $l_{4}+1086 l_{4}^{2}$ \\
\hline Male & $-459+905.1 l_{1}$ & $997.2-598.5 l_{1}$ & $867.3+826.7 l_{1}-$ \\
& $-371.6 l_{1}^{2}$ & $-1441.1 l_{2}+1119.9$ & $5307.9 l_{2}+6982.2 l_{3}$ \\
& & $l_{2}^{2}$ & $-4251.27 l_{4}+960.78$ \\
& & $l_{4}^{2}$
\end{tabular}

\begin{tabular}{|c|c|c|c|c|}
\hline Bihar & $\begin{array}{c}\text { Total/Pers } \\
\text { on }\end{array}$ & $\begin{array}{c}-2119.1+4389.2 l_{1} \\
-2199.2 l_{1}^{2}\end{array}$ & $\begin{array}{c}-1110.9-164.1 l_{1} \\
+2548.4 l_{2}-1202.1 l_{2}^{2}\end{array}$ & $\begin{array}{c}-588.79-1386.83 l_{1} \\
+8453.90 l_{2} \\
-14739.7 l_{3}+9031.8 \\
l_{4}-700.2 l_{4}^{2} \\
-97.8-136.6 l_{1} \\
+6385.8 l_{2}-9658.8 l_{3} \\
+4907.5 l_{4}-197.9 l_{4}^{2}\end{array}$ \\
\hline \multirow{3}{*}{ Gujarat } & Male & $\begin{array}{c}4556.3-9727.9 l_{1} \\
+5264 l_{1}^{2}\end{array}$ & $\begin{array}{c}3863-212.8 l_{1} \\
-8008.7 l_{2}+4449 l_{2}^{2}\end{array}$ & $\begin{array}{c}2850.8+2508.1 l_{1}^{-} \\
14816 l_{2}+24467.2 l_{3} \\
18321.2 l_{4}+3390.5 l_{4}^{2}\end{array}$ \\
\hline & Female & $\begin{array}{c}-106.3+158 l_{1} \\
+28.8 l_{1}^{2}\end{array}$ & $\begin{array}{c}518.7-486.5 l_{1} \\
+1710 l_{2}-631.9 l_{2}^{2}\end{array}$ & $\begin{array}{c}120.4-525.2 l_{1} \\
+1085.1 l_{2} \\
-1331.7 l_{3}+636.3 l_{4} \\
+90.6 l_{4}^{2}\end{array}$ \\
\hline & $\begin{array}{c}\text { Total/Pers } \\
\text { on }\end{array}$ & $\begin{array}{l}1536.0-3332.8 l_{1} \\
\quad+1881.2 l_{1}^{2}\end{array}$ & $\begin{array}{c}1605.4-304.6 l_{1} \\
-3071.2 l_{2}-1852.5 l_{2}^{2}\end{array}$ & $\begin{array}{c}897.4-923.5 l_{1} \\
+3388.6 l_{2} \\
-4088.2 l_{3}-262.4 l_{4} \\
+1068.0 l_{4}^{2}\end{array}$ \\
\hline & Male & $\begin{array}{c}-1104.1+2368.1 l_{1} \\
-1196.0 l_{1}^{2}\end{array}$ & $\begin{array}{c}-581.8+65 l_{1} \\
+1214.5 l_{2}-628.7 l_{2}^{2}\end{array}$ & $\begin{array}{c}-1858.3+167.2 l_{1}- \\
1136.4 l_{2} \\
+4059.1 l_{3}+845.1 l_{4} \\
-2010.8 l_{4}^{2}\end{array}$ \\
\hline Haryana & Female & $\begin{array}{c}-1949.3+4157.9 l_{1} \\
-2138.1 l_{1}^{2}\end{array}$ & $\begin{array}{c}478.2-395.0 l_{1} \\
-498.6 l_{2}+491.6 l_{2}^{2}\end{array}$ & $\begin{array}{c}785.7+392.3 l_{1}- \\
4558.5 l_{2} \\
+8518.5 l_{3}-5922 l_{4}\end{array}$ \\
\hline
\end{tabular}




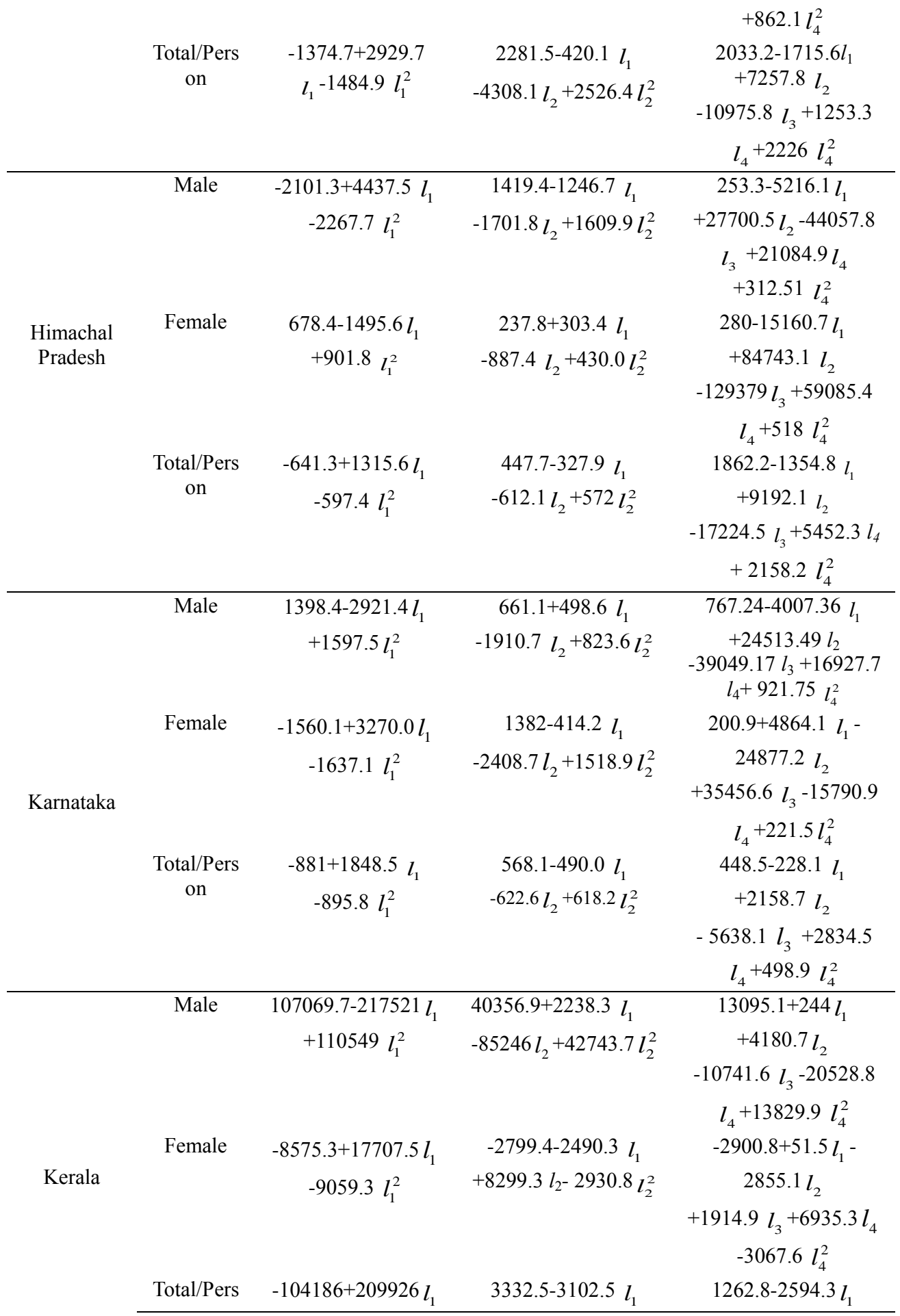




\begin{tabular}{|c|c|c|c|c|}
\hline & on & $-105667 l_{1}^{2}$ & $-2976.8 l_{2}+2817.6 l_{2}^{2}$ & $\begin{array}{c}+12078.1 l_{2} \\
-23632.3 l_{3}+12191.6 l_{4} \\
+765.3 l_{4}^{2}\end{array}$ \\
\hline \multirow{3}{*}{$\begin{array}{l}\text { Madhya } \\
\text { Pradesh }\end{array}$} & Male & $\begin{array}{c}-546.4+1184 l_{1} \\
-570.0 l_{1}^{2}\end{array}$ & $\begin{array}{c}-349.5-62.2 l_{1} \\
+855.9 l_{2}-376.7 l_{2}^{2}\end{array}$ & $\begin{array}{c}-232.19-386.81 l_{1} \\
+1752.63 l_{2} \\
-2083.63 l_{3}-1249.80 \\
l_{4}-231.35 l_{4}^{2}\end{array}$ \\
\hline & Female & $\begin{array}{c}-779.3+1639.2 l_{1} \\
-786.5 l_{1}^{2}\end{array}$ & $\begin{array}{r}-76.0-275.2 l_{1} \\
+494.7 l_{2}-68.7 l_{2}^{2}\end{array}$ & $\begin{array}{c}-95+1155.7 l_{1^{-}} \\
5824.1 l_{2} \\
+8135.1 l_{3}-3221.7 l_{4}- \\
74.8 l_{4}^{2}\end{array}$ \\
\hline & $\begin{array}{c}\text { Total } / \text { Pers } \\
\text { on }\end{array}$ & $\begin{array}{c}-262.9+0.0061 l_{1} \\
-2.8 \mathrm{E}-08 l_{1}^{2}\end{array}$ & $\begin{array}{c}-299.1+0.002 l_{1} \\
-475.6 l_{2}-342.1 l_{2}^{2}\end{array}$ & $\begin{array}{c}-152.6+0.05 l_{1}- \\
2864.7 l_{2} \\
+10508.2 l_{3}-12690.2 \\
l_{4}-177.8 l_{4}^{2}\end{array}$ \\
\hline \multirow{3}{*}{ Maharashtra } & Male & $\begin{array}{c}1836.0-3866.6 l_{1} \\
+2106.9 l_{1}^{2}\end{array}$ & $\begin{array}{c}1121.8+1372 l_{1} \\
-2391.7 l_{2}+1331.7 l_{2}^{2}\end{array}$ & $\begin{array}{c}781.76+1488.23 l_{1}^{-} \\
6631.56 l_{2} \\
-8715.32 l_{3}-5234.6 \\
l_{4}+956.25 l_{4}^{2}\end{array}$ \\
\hline & Female & $\begin{array}{c}-1001.4+2021.2 l_{1} \\
-942.6 l_{1}^{2}\end{array}$ & $\begin{array}{c}-608.1-235.6 l_{1} \\
+1500.5 l_{2}-580 l_{2}^{2}\end{array}$ & $\begin{array}{c}-127.1-669.3 l_{1} \\
+1339.3 l_{2} \\
+966.9 l_{3}-1411.1 l_{4}- \\
21.1 l_{4}^{2}\end{array}$ \\
\hline & $\begin{array}{c}\text { Total } / \text { Pers } \\
\text { on }\end{array}$ & $\begin{array}{c}477.4-1049.8 l_{1} \\
+649.1 l_{1}^{2}\end{array}$ & $\begin{array}{c}115.1-96.3 l_{1} \\
-172.6 l_{2}+229.9 l_{2}^{2}\end{array}$ & $\begin{array}{c}978.6-1948.6 l_{1} \\
+6250.4 l_{2} \\
-2608.09 l_{3}-3860 l_{4} \\
+1259 l_{4}^{2}\end{array}$ \\
\hline \multirow{3}{*}{ Odisha } & Male & $\begin{array}{c}-767.8+1720.6 l_{1} \\
-887.3 l_{1}^{2}\end{array}$ & $\begin{array}{c}-489.5+371.8 l_{1} \\
+724.8 l_{2}-541.0 l_{2}^{2}\end{array}$ & $\begin{array}{c}40.66-4377.38 l_{1} \\
+23321.57 l_{2} \\
-34178.2 l_{3}+15120.9 \\
l_{4}-146.05 l_{4}^{2}\end{array}$ \\
\hline & Female & $\begin{array}{c}-577.5+1173.8 l_{1} \\
-520.8 l_{1}^{2}\end{array}$ & $\begin{array}{c}-191.2-78.4 l_{1} \\
+468.8 l_{2}-122.4 l_{2}^{2}\end{array}$ & $\begin{array}{c}20.8-389.7 l_{1}+1306.3 l_{2} \\
-2546.6 l_{3}+1642.2 \\
l_{4}+43.8 l_{4}^{2}\end{array}$ \\
\hline & $\begin{array}{c}\text { Total } / \text { Pers } \\
\text { on }\end{array}$ & $\begin{array}{c}-249.6+493.9 l_{1} \\
-170 l_{1}^{2}\end{array}$ & $\begin{array}{c}-210.5+193 l_{1} \\
+217.1 l_{2}-125.2 l_{2}^{2}\end{array}$ & $\begin{array}{c}-196.5-315.4 l_{1} \\
+3123.8 l_{2} \\
-5325.7 l_{3}+2906.8 \\
l_{4}-118.7 l_{4}^{2}\end{array}$ \\
\hline
\end{tabular}




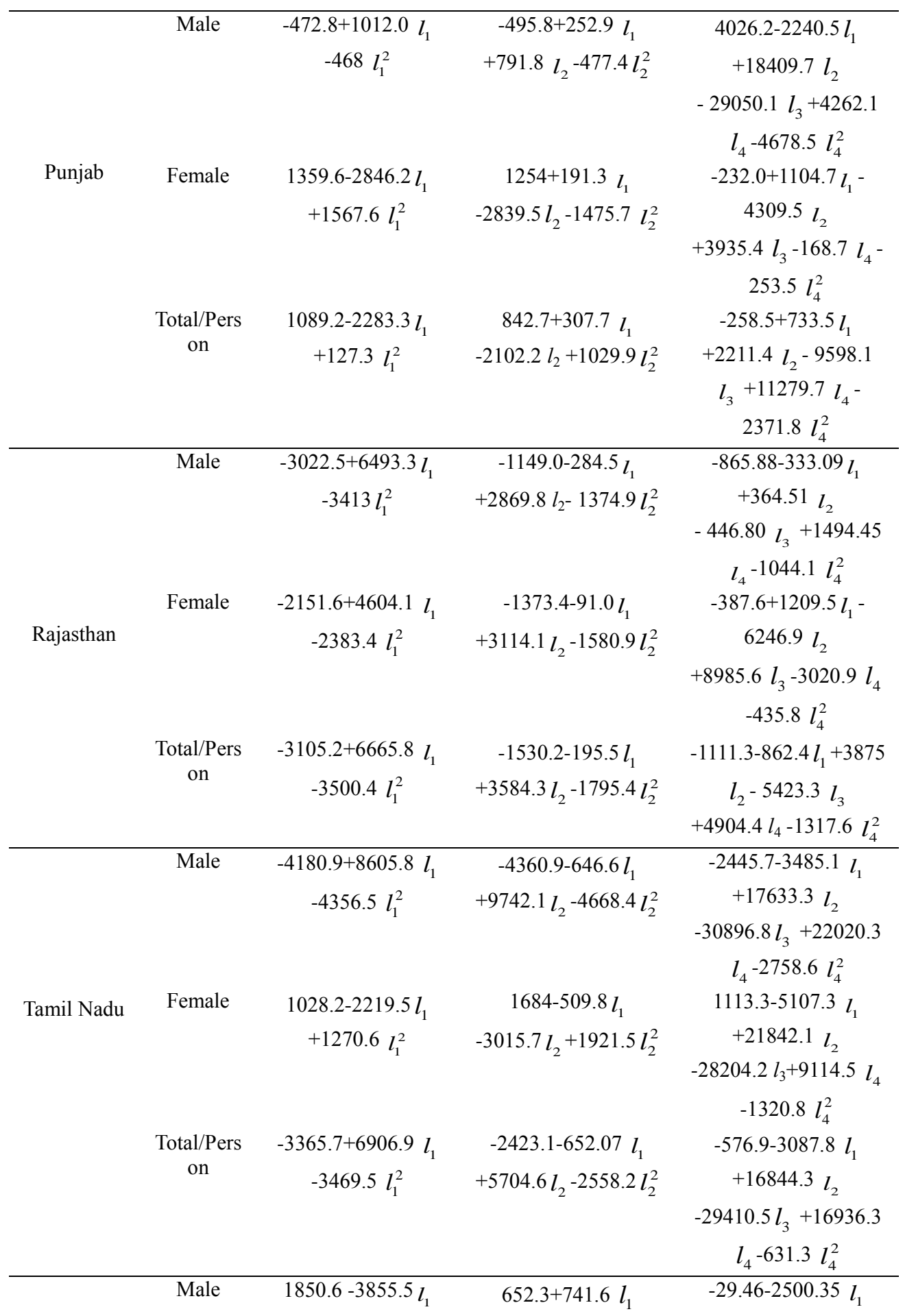




\begin{tabular}{|c|c|c|c|c|}
\hline \multirow{3}{*}{$\begin{array}{c}\text { Uttar } \\
\text { Pradesh }\end{array}$} & & $+2075.8 l_{1}^{2}$ & $-2140.3 l_{2}+814.5 l_{2}^{2}$ & $\begin{array}{c}+12372.56 l_{2} \\
-18728.6 l_{3} \\
+9038.157 l_{4}-85.63 l_{4}^{2}\end{array}$ \\
\hline & Female & $\begin{array}{c}-6550.5+13614.3 l_{1} \\
-7003.4 l_{1}^{2}\end{array}$ & $\begin{array}{c}-1368-387.9 l_{1} \\
+3253.7 l_{2}-1428.9 l_{2}^{2}\end{array}$ & $\begin{array}{c}306.8+2349.7 l_{1}- \\
9448.7 l_{2} \\
+11108.6 l_{3}-4672.4 l_{4} \\
+435.4 l_{4}^{2}\end{array}$ \\
\hline & $\begin{array}{l}\text { Total/Pers } \\
\text { on }\end{array}$ & $\begin{array}{c}-726.9+1517.2 l_{1} \\
-717.9 l_{1}^{2}\end{array}$ & $\begin{array}{c}-576.3-197.7 l_{1} \\
+1521.2 l_{2}-680.9 l_{2}^{2}\end{array}$ & $\begin{array}{c}-197.2-714.2 l_{1} \\
+6459.3 l_{2} \\
-13574.1 l_{3}+8367.8 \\
l_{4}-273.4 l_{4}^{2}\end{array}$ \\
\hline \multirow{3}{*}{$\begin{array}{c}\text { West } \\
\text { Bengal }\end{array}$} & Male & $\begin{array}{l}730.9-1559.6 \\
l_{1}+904.61 l_{1}^{2}\end{array}$ & $\begin{array}{c}1103.0-495.5 l_{1} \\
-1777.1 l_{2}+1245.3 l_{2}^{2}\end{array}$ & $\begin{array}{c}773.83-4005.6 l_{1} \\
+19510.33 l_{2} \\
-29189.8 l_{3} \\
+12121.17 l_{4}+865.28 \\
l_{4}^{2} \\
-17465-54161\end{array}$ \\
\hline & Female & $\begin{array}{c}-6767.6+13993.3 l_{1} \\
-7157.3 l_{1}^{2}\end{array}$ & $\begin{array}{r}-1647.4-426.8 l_{1} \\
+3906.7 l_{2}-1759.6 l_{2}^{2}\end{array}$ & $\begin{array}{c}-1746.5-541.6 l_{1} \\
+2913.4 l_{2} \\
-5154.2 l_{3}+6482.2 l_{4} \\
-1881 l_{4}^{2}\end{array}$ \\
\hline & $\begin{array}{c}\text { Total/Pers } \\
\text { on }\end{array}$ & $\begin{array}{c}-1739.5+3573.4 l_{1} \\
-1760.7 l_{1}^{2}\end{array}$ & $\begin{array}{c}247.8-560.4 l_{1} \\
+98.3 l_{2}+289.0 l_{2}^{2}\end{array}$ & $\begin{array}{c}1.3+434.3 l_{1}-3266.82 l_{2} \\
+4296.48 l_{3}-1393.85 \\
l_{4}+2.71 l_{4}^{2}\end{array}$ \\
\hline \multirow{3}{*}{ India } & Male & $\begin{array}{c}-124.7+226.2 l_{1} \\
-27.8 l_{1}^{2}\end{array}$ & $\begin{array}{r}275.3-509.3 l_{1} \\
+6.6 l_{2}+299.3 l_{2}^{2}\end{array}$ & $\begin{array}{c}373.93-63547 l_{1}- \\
2226.95 l_{2} \\
+8750.46 l_{3}-6657.64 \\
l_{4}-468.68 l_{4}^{2}\end{array}$ \\
\hline & Female & $\begin{array}{c}-2909.7+6090.5 l_{1} \\
-3111 l_{1}^{2}\end{array}$ & $\begin{array}{c}-771.9-213.0 l_{1} \\
+1886.8 l_{2}-827.9 l_{2}^{2}\end{array}$ & $\begin{array}{c}-275.1-1149.5 l_{1} \\
+7102.7 l_{2} \\
-12686.1 l_{3}+7389.1 l_{4} \\
-306.1 l_{4}^{2}\end{array}$ \\
\hline & $\begin{array}{c}\text { Total/Pers } \\
\text { on }\end{array}$ & $\begin{array}{c}-1359.6+2822.6 l_{1} \\
-139058 l_{1}^{2}\end{array}$ & $\begin{aligned} & -147.4-337.6 l_{1} \\
+ & 704 l_{2}-145.5 l_{2}^{2}\end{aligned}$ & $\begin{array}{c}-75.7-125 l_{1}-235.6 l_{2} \\
+442.0 l_{3}+138 l_{4}^{-} \\
70.2 l_{4}^{2}\end{array}$ \\
\hline
\end{tabular}

In order to observe the relative performances of all the three polynomial regression models (2-4), tables are presented with $R^{2}$ and SE values - Tables 4-6.

Again, $e_{0}$ of India and the 16 Indian states are estimated using the fitted polynomial regressions for each of the states and India as estimating equations. These equations are 
obtained from models (2-4). The values of $l_{1}, l_{2}, l_{3}$ and $l_{4}$ are taken from SRS tables of 2001-05 and 2011-15 and thus the estimated values of $e_{0}$ are presented along with corresponding values of $e_{0}$ from the SRS tables. In this estimation, only the SRS data, total of male and female, is used, and the results are presented in Table 8.

\subsubsection{Estimation of district level $e_{0}$ of Assam by using the following indirect estimation technique}

Finally, by using Trussell's variant of Brass method, [17]), child mortality estimates $q_{x}$ are obtained from CEB, CS of census data 2001 and 2011 for every district of Assam. From these estimates of $q_{x}, l_{x}$ are obtained by $l_{x}=1-q_{x}$ and these $l_{x}, x=2,3,5$ are smoothed with logit smoothing [15]. Then, using the smoothed values of $l_{x}$, improved estimates of $l_{x}, x=1,2,3,5$ are obtained by fitting two parameter Weibull survival function $[13,16,18]$.

Then, the estimated $l_{1}$ and $l_{1}$ are used in the equations $e_{0}=342.5-813.7 l_{1}+548.4 l_{1}^{2}$ and $e_{0}=109.51-141.37 l_{1}-137.328 l_{2}+247.05 l_{2}^{2}$, which are obtained from models (2) and (3) respectively, and particularly fitted for the Assam State (based on the same SRS data, total of male and female). The estimated $e_{0}$ for the years 2001 and 2011 are presented in Table 7.

\section{Results and Discussion}

In section 2.2.1, as mentioned in the introduction, the extensive empirical investigation is aimed at examining how far some commonly used techniques, such as using $e_{0}$ and infant mortality rates for estimating life expectancies at other ages, works realistically, particularly, in the case of the SRS-based life tables of Assam. The investigation deals with males, females and total of males and females of the stated period. The results are presented in Tables 1-3.

In Table 1, the data used is the SRS-based total of male and female life tables of Assam. It can be observed that natural logarithm of life expectancies at ages 15 and 35 taken as explanatory variables to the response variable $\ln (L E(x))$ for all $x$ can give better fitting in the range of age groups (0-55) than that of Kesarwani's procedure. Moreover, logarithm of life expectancy at $x=1$, too, taken as explanatory variable to the response variable $\ln (L E(x))$ for all $x$ fits better than that of Kesarwani's procedure. However, $\ln (L E(x))$ at $x=15,35$ as explanatory variables provide relatively better estimates than that of all the others.

In Table 2, the data used is the SRS-based male life tables of Assam. Natural logarithm of life expectancy at age 30 can give better estimation in the range of age groups (0-50) than that of Kesarwani's procedure, and besides, logarithm of life expectancies at $x=35$, 40 provide better estimates than that of Kesarwani's procedure. Even logarithm of life expectancy at $x=30$ can give relatively better estimates than that of Kesarwani's procedure and logarithm of life expectancy at age $x=35,40$. 
In Table 3, the data used is the SRS-based female life tables of Assam. $\ln (\operatorname{LE}(x))$ at $x=$ $1,5,15$ used as explanatory variables can provide better estimates than that of the rest and Kesarwani's procedure.

Thus in this comprehensive investigation in the particular case of SRS-based life tables of Assam when fifty-four life tables are taken- 18 for male, 18 for female and 18 for the combined - together, it is observed how some widely used techniques are not performing well. Rather some new models are fitting better in the particular context of the data.

In 2.2.2, the two polynomial regression models (3) and (4) which are proposed in this paper are illustrated by fitting to the abovementioned SRS-based life tables. Fifty four life tables of 1995-99 to 2012-16 for each state and India are used. For every state 18 life tables for male, 18 life tables for female and 18 life tables for the total are taken. By fitting the polynomial regression models (3) and (4), equations for estimating $e_{0}$ are obtained for India and all her 16 states in all categories - male, female and the total. The results provided by these two polynomial regression models and the result provided by quadratic regression model (2) are all presented in Tables 4-6. The table shows $R^{2}$ and S. E values. It is seen that these two polynomial regression models (3) and (4) obtained in this paper have provided better fit than the quadratic polynomial regression model (2) does in the context of the data used. Among these two proposed polynomials too, model (4) performs better than model (3).

In section 2.2.3, district level $e_{0}$ values of Assam state are estimated for the years 2001 and 2011 by using the fitted equation $e_{0}=109.51-141.37 l_{1}-137.328_{l_{2}}+247.05 l_{2}^{2}$ obtained from model (3), whereas $l_{1}$ and $l_{2}$ are estimated from CEB, CS of both census years by using indirect technique of estimation mentioned in the section. The $e_{0}$ values so estimated are presented in Table 7 along with $e_{0}$ values estimated by $e_{0}=342.5-813.7 l_{1}+548.4 l_{1}^{2}$ obtained from model (2). By seeing the closeness of the corresponding estimates provided by the proposed model (3) and quadratic regression model, the reliability of the estimates provided by the proposed model (3) can be acknowledged.

Table 1. $\mathrm{R}^{2}$ and $\mathrm{SE}$ values for Assam, total of male and female.

\begin{tabular}{|c|c|c|c|c|c|c|c|c|}
\hline \multirow[t]{2}{*}{$L E(x)$} & \multicolumn{2}{|c|}{$\begin{array}{c}\ln (\operatorname{LE}(x)) \\
=\alpha+\beta * \ln (\operatorname{LE}(1))\end{array}$} & \multicolumn{2}{|c|}{$\begin{array}{c}\ln (\operatorname{LE}(x)) \\
=\alpha+\beta * \ln (\operatorname{LE}(15))\end{array}$} & \multicolumn{2}{|c|}{$\begin{array}{c}\ln (\operatorname{LE}(x)) \\
=\alpha+\beta * \ln (L E(35))\end{array}$} & \multicolumn{2}{|c|}{$\begin{array}{c}\text { Kesarwani's } \\
\text { Method }\end{array}$} \\
\hline & $\mathrm{R}^{2}$ & $\mathrm{SE}$ & $\mathrm{R}^{2}$ & SE & $\mathrm{R}^{2}$ & SE & $\mathrm{R}^{2}$ & SE \\
\hline $\mathrm{LE}(0)$ & 0.9882 & 0.0048 & 0.9893 & 0.0046 & 0.9883 & 0.0030 & 0.9023 & 0.0115 \\
\hline LE(1) & 0.8687 & 0.0012 & 0.9852 & 0.0039 & 0.9917 & 0.0029 & 0.9880 & 0.0035 \\
\hline LE(5) & 0.8786 & 0.0013 & 0.9731 & 0.0015 & 0.8869 & 0.0125 & 0.8014 & 0.0165 \\
\hline LE(10) & 0.9990 & 0.0025 & 0.9988 & 0.0008 & 0.9938 & 0.0020 & 0.9026 & 0.0081 \\
\hline $\mathrm{LE}(15)$ & 0.9852 & 0.0033 & 0.9053 & 0.0083 & 0.9916 & 0.0025 & 0.9053 & 0.0083 \\
\hline $\operatorname{LE}(20)$ & 0.9931 & 0.0023 & 0.9964 & 0.0016 & 0.9944 & 0.0021 & 0.9003 & 0.0086 \\
\hline LE(25) & 0.9878 & 0.0030 & 0.9950 & 0.0019 & 0.9978 & 0.0013 & 0.8988 & 0.0087 \\
\hline LE(30) & 0.9864 & 0.0032 & 0.9919 & 0.0025 & 0.9979 & 0.0013 & 0.8828 & 0.0095 \\
\hline LE(35) & 0.9917 & 0.0026 & 0.9916 & 0.0026 & 0.8816 & 0.0096 & 0.8882 & 0.0096 \\
\hline $\mathrm{LE}(40)$ & 0.9859 & 0.0036 & 0.9848 & 0.0037 & 0.9960 & 0.0019 & 0.8637 & 0.0111 \\
\hline $\mathrm{LE}(45)$ & 0.9804 & 0.0042 & 0.9813 & 0.0041 & 0.9942 & 0.0023 & 0.8760 & 0.0106 \\
\hline $\operatorname{LE}(50)$ & 0.9628 & 0.0060 & 0.9713 & 0.0054 & 0.9835 & 0.0041 & 0.9138 & 0.0093 \\
\hline $\operatorname{LE}(55)$ & 0.9391 & 0.0081 & 0.9497 & 0.0073 & 0.9661 & 0.0060 & 0.8764 & 0.0115 \\
\hline
\end{tabular}


334 Methods for Estimating Life Expectancy

\begin{tabular}{lllllllll} 
LE(60) & 0.9113 & 0.0099 & 0.9125 & 0.0098 & 0.9416 & 0.0080 & 0.8348 & 0.0135 \\
LE(65) & 0.6354 & 0.0176 & 0.6784 & 0.0165 & 0.6958 & 0.0161 & 0.6010 & 0.0184 \\
LE(70) & 0.4023 & 0.0207 & 0.0372 & 0.0212 & 0.4278 & 0.0203 & 0.3283 & 0.0220 \\
LE(75) & 0.0534 & 0.0308 & 0.0304 & 0.0312 & 0.0561 & 0.0308 & 0.0695 & 0.0306 \\
LE(80) & 0.0045 & 0.0699 & 0.0160 & 0.0695 & 0.0051 & 0.0699 & $6.9 E-05$ & 0.0701 \\
LE(85) & 0.0351 & 0.1044 & 0.0597 & 0.1030 & 0.0377 & 0.1042 & 0.0115 & 0.1056 \\
\hline
\end{tabular}

Table 2. $\mathrm{R}^{2}$ and $\mathrm{SE}$ values for Assam, male.

\begin{tabular}{|c|c|c|c|c|c|c|c|c|}
\hline \multirow[t]{2}{*}{$L E(x)$} & \multicolumn{2}{|c|}{$\begin{array}{c}\ln (\operatorname{LE}(x)) \\
=\alpha+\beta * \ln (L E(30))\end{array}$} & \multicolumn{2}{|c|}{$\begin{array}{c}\ln (L E(x)) \\
=\alpha+\beta * \ln (L E(35))\end{array}$} & \multicolumn{2}{|c|}{$\begin{array}{c}\ln (\operatorname{LE}(x)) \\
=\alpha+\beta * \ln (L E(40))\end{array}$} & \multicolumn{2}{|c|}{$\begin{array}{l}\text { Kesarwani's } \\
\text { Method }\end{array}$} \\
\hline & $R^{2}$ & $\mathrm{SE}$ & $R^{2}$ & SE & $R^{2}$ & SE & $R^{2}$ & SE \\
\hline $\mathrm{LE}(0)$ & 0.9475 & 0.0089 & 0.9512 & 0.0085 & 0.9358 & 0.0098 & 0.8901 & 0.0128 \\
\hline LE(1) & 0.9856 & 0.0032 & 0.9867 & 0.0030 & 0.9724 & .0044 & 0.7638 & 0.0130 \\
\hline $\mathrm{LE}(5)$ & 0.9887 & 0.0024 & 0.9931 & 0.0018 & 0.9813 & 0.0030 & 0.7654 & 0.0107 \\
\hline $\mathrm{LE}(10)$ & 0.9876 & 0.0021 & 0.9925 & 0.0017 & 0.9847 & 0.0024 & 0.7120 & 0.0101 \\
\hline LE(15) & 0.9874 & 0.0022 & 0.9912 & 0.0019 & 0.9864 & 0.0023 & 0.7109 & 0.0106 \\
\hline LE(20) & 0.9920 & 0.0018 & 0.9937 & 0.0016 & 0.9817 & 0.0028 & 0.7295 & 0.0107 \\
\hline $\mathrm{LE}(25)$ & 0.9940 & 0.0016 & 0.9936 & 0.0016 & 0.9897 & 0.0021 & 0.6944 & 0.0113 \\
\hline $\mathrm{LE}(30)$ & 0.9620 & 0.0040 & 0.9916 & 0.0019 & 0.9916 & 0.0019 & 0.7300 & 0.0110 \\
\hline LE(35) & 0.9980 & 0.0010 & 0.7376 & 0.012 & 0.9894 & 0.0024 & 0.7368 & 0.0117 \\
\hline LE(40) & 0.9916 & 0.0022 & 0.9894 & 0.0025 & 0.7199 & 0.0126 & 0.7199 & 0.0126 \\
\hline LE(45) & 0.9645 & 0.0048 & 0.9644 & 0.0048 & 0.9742 & 0.0041 & 0.8158 & 0.0109 \\
\hline $\mathrm{LE}(50)$ & 0.9468 & 0.0065 & 0.9323 & 0.0065 & 0.9439 & 0.0059 & 0.8438 & 0.0010 \\
\hline LE(55) & 0.8876 & 0.0083 & 0.8817 & 0.0085 & 0.9097 & 0.0074 & 0.7367 & 0.0127 \\
\hline LE(60) & 0.9196 & 0.0079 & 0.9085 & 0.0084 & 0.9328 & 0.0072 & 0.7612 & 0.0136 \\
\hline LE(65) & 0.4286 & 0.0185 & 0.4167 & 0.0187 & 0.4811 & 0.0176 & 0.3084 & 0.0203 \\
\hline $\mathrm{LE}(70)$ & 0.0003 & 0.0277 & $.001 \mathrm{E}-02$ & 0.0277 & 0.0030 & 0.0276 & 0.0048 & 0.0276 \\
\hline LE(75) & 0.3705 & 0.0207 & 0.3783 & 0.0305 & 0.3180 & 0.0197 & 0.3176 & 0.0319 \\
\hline LE(80) & 0.6727 & 0.0421 & 0.6618 & 0.0428 & 0.6740 & 0.0420 & 0.3300 & 0.0603 \\
\hline LE(85) & 0.7433 & 0.0581 & 0.3912 & 0.0895 & 0.3910 & 0.0895 & 0.3912 & 0.0895 \\
\hline
\end{tabular}

Table 3. $\mathrm{R}^{2}$ and SE values for Assam, female.

\begin{tabular}{|c|c|c|c|c|c|c|c|c|}
\hline \multirow{3}{*}{$L E(x)$} & \multicolumn{2}{|c|}{$\ln (\operatorname{LE}(x))$} & \multicolumn{2}{|c|}{$\ln (L E(x))$} & \multicolumn{2}{|c|}{$\ln (L E(x))$} & \multicolumn{2}{|c|}{ Kesarwani's } \\
\hline & \multicolumn{8}{|c|}{$=\alpha+\beta * \ln (L E(1))=\alpha+\beta * \ln (L E(5))=\alpha+\beta * \ln (L E(15))$} \\
\hline & $R^{2}$ & SE & $R^{2}$ & SE & $R^{2}$ & SE & $R^{2}$ & SE \\
\hline $\mathrm{LE}(0)$ & 0.9939 & 0.0040 & 0.9945 & 0.0038 & 0.9903 & 0.0050 & 0.9137 & 0.0120 \\
\hline LE(1) & 0.6607 & 0.0228 & 0.9893 & 0.0040 & 0.9813 & 0.0053 & 0.9030 & 0.0122 \\
\hline LE(5) & 0.9893 & 0.0038 & 0.7870 & 0.0171 & 0.8383 & 0.0149 & 0.8237 & 0.0156 \\
\hline LE $(10)$ & 0.9883 & 0.0037 & 0.9987 & 0.0013 & 0.9987 & 0.0013 & 0.9373 & 0.0087 \\
\hline LE(15) & 0.9813 & 0.0049 & 0.9979 & 0.00163 & 0.9440 & 085 & 0.9440 & 0.0085 \\
\hline LE(20) & 0.9817 & 0.0049 & 0.9973 & 9 & 0.9 & 0.0 & 0.9269 & 0.0098 \\
\hline LE(25) & 0.9657 & 0.0065 & 0.9900 & 0.0036 & 0.9934 & 0.0030 & 0.9141 & 0.0107 \\
\hline $\operatorname{LE}(30)$ & 0.9721 & 0.0060 & 0.9857 & 0.0044 & 0.9865 & 0.0043 & 0.8858 & 0.0125 \\
\hline $\mathrm{LE}(35)$ & 0.9749 & 0.0057 & 0.9857 & 0.0043 & 0.9858 & 0.0043 & 0.8867 & 0.0122 \\
\hline LE $(40)$ & 0.9677 & 0.0070 & 0.9734 & 0.0064 & 0.9715 & 0.0066 & 0.9734 & 0.0064 \\
\hline LE(45) & 0.9632 & 0.0073 & 0.9662 & 0.0069 & 0.9650 & 0.0071 & 0.9662 & 0.0069 \\
\hline LE $(50)$ & 0.9379 & 0.0104 & 0.9459 & 0.0097 & 0.9488 & 0.0099 & 0.9459 & 0.0097 \\
\hline $\operatorname{LE}(55)$ & 0.9205 & 0.0132 & 0.9269 & 0.0126 & 0.9550 & 0.0128 & 0.9269 & 0.0127 \\
\hline
\end{tabular}




\begin{tabular}{lllllllll} 
LE(60) & 0.8625 & 0.0172 & 0.8735 & 0.0165 & 0.8730 & 0.0166 & 0.8735 & 0.0165 \\
LE(65) & 0.7185 & 0.0236 & 0.7444 & 0.0225 & 0.7540 & 0.0221 & 0.7444 & 0.0225 \\
LE(70) & 0.5451 & 0.0409 & 0.5507 & 0.0406 & 0.5403 & 0.0409 & 0.5507 & 0.0406 \\
LE(75) & 0.3406 & 0.0740 & 0.3117 & 0.0756 & 0.2957 & 0.0765 & 0.3117 & 0.0756 \\
LE(80) & 0.2477 & 0.1215 & 0.2307 & 0.1229 & 0.2171 & 0.1239 & 0.2307 & 0.1229 \\
LE(85) & 0.1860 & 0.1728 & 0.1677 & 0.1747 & 0.1545 & 0.1761 & 0.1677 & 0.1747 \\
\hline
\end{tabular}

Table 4. $R^{2}$ and SE values for the polynomial regression models, total of male and female.

\begin{tabular}{ccccccc}
\hline States & \multicolumn{2}{c}{ Model (2) } & \multicolumn{2}{c}{ Model (3) } & \multicolumn{2}{c}{ Model (4) } \\
\cline { 2 - 7 } & $R^{2}$ & SE & $R^{2}$ & SE & $R^{2}$ & SE \\
\hline Andhra Pradesh & 0.8759 & 0.8086 & 0.9276 & 0.6298 & 0.9970 & 0.1387 \\
Assam & 0.9306 & 0.7401 & 0.9770 & 0.4413 & 0.9972 & 0.1653 \\
Bihar & 0.9566 & 0.6021 & 0.9968 & 0.1629 & 0.9971 & 0.1737 \\
Gujarat & 0.9639 & 0.3514 & 0.9966 & 0.1109 & 0.9971 & 0.1120 \\
Haryana & 0.8128 & 0.6870 & 0.9799 & 0.2329 & 0.9806 & 0.2471 \\
Himachal Pradesh & 0.9292 & 0.4389 & 0.9432 & 0.4067 & 0.9856 & 0.2215 \\
Karnataka & 0.9232 & 0.4964 & 0.9803 & 0.2605 & 0.9854 & 0.2416 \\
Kerala & 0.4613 & 0.9309 & 0.8094 & 0.5732 & 0.9499 & 0.3173 \\
Madhya Pradesh & 0.9956 & 0.1951 & 0.9964 & 0.1823 & 0.9968 & 0.1861 \\
Maharashtra & 0.9875 & 0.2715 & 0.9943 & 0.1837 & 0.9982 & 0.1157 \\
Odisha & 0.9970 & 0.1687 & 0.9970 & 0.1754 & 0.9972 & 0.1813 \\
Punjab & 0.9088 & 0.6218 & 0.9089 & 0.6440 & 0.9735 & 0.3744 \\
Rajasthan & 0.9145 & 0.6491 & 0.9980 & 0.1026 & 0.9982 & 0.1044 \\
Tamil Nadu & 0.9710 & 0.4038 & 0.9856 & 0.2950 & 0.9889 & 0.2798 \\
Uttar Pradesh & 0.9392 & 0.5163 & 0.9938 & 0.1712 & 0.9975 & 0.11652 \\
West Bengal & 0.9634 & 0.4429 & 0.9953 & 0.1638 & 0.9970 & 0.1412 \\
India & 0.9795 & 0.3445 & 0.9965 & 0.1469 & 0.9965 & 0.1586 \\
\hline
\end{tabular}

Table 5. $\quad R^{2}$ and SE values for the polynomial regression models, male.

\begin{tabular}{ccccccc}
\hline \multirow{2}{*}{ States } & \multicolumn{2}{c}{ Model (2) } & \multicolumn{2}{c}{ Model (3) } & \multicolumn{2}{c}{ Model (4) } \\
\cline { 2 - 7 } & $\boldsymbol{R}^{2}$ & SE & $\boldsymbol{R}^{2}$ & SE & $\boldsymbol{R}^{2}$ & SE \\
\hline Andhra Pradesh & 0.4088 & 1.1828 & 0.8277 & 0.6618 & 0.9284 & 0.4601 \\
Assam & 0.8837 & 0.8219 & 0.9465 & 0.5769 & 0.9839 & 0.3423 \\
Bihar & 0.9461 & 0.6165 & 0.9896 & 0.2798 & 0.9909 & 0.2839 \\
Gujarat & 0.9058 & 0.5879 & 0.9269 & 0.5359 & 0.9297 & 0.5677 \\
Haryana & 0.7181 & 0.5754 & 0.7184 & 0.5907 & 0.8648 & 0.4422 \\
Himachal Pradesh & 0.7847 & 0.7560 & 0.8680 & 0.5207 & 0.9216 & 0.43256 \\
Karnataka & 0.7363 & 0.7519 & 0.8856 & 0.5126 & 0.9206 & 0.4613 \\
Kerala & 0.8902 & 0.3921 & 0.9379 & 0.3052 & 0.9620 & 0.2581 \\
Madhya Pradesh & 0.9898 & 0.2498 & 0.9912 & 0.2411 & 0.9912 & 0.2606 \\
Maharashtra & 0.9851 & 0.2871 & 0.9889 & 0.2566 & 0.9911 & 0.2482 \\
Odisha & 0.8994 & 0.4643 & 0.9129 & 0.4473 & 0.9969 & 0.1811 \\
Punjab & 0.3868 & 1.4984 & 0.3874 & 1.550 & 0.6333 & 1.2954 \\
Rajasthan & 0.8760 & 0.6586 & 0.9852 & 0.2354 & 0.9873 & 0.2355 \\
Tamil Nadu & 0.9231 & 0.5806 & 0.9539 & 0.4654 & 0.9641 & 0.4434 \\
Uttar Pradesh & 0.4252 & 1.1272 & 0.82717 & 0.6398 & 0.9894 & 0.1710 \\
West Bengal & 0.9541 & 0.5001 & 0.9890 & 0.2537 & 0.9905 & 0.2550 \\
India & 0.9793 & 0.1817 & 0.9926 & 0.1884 & 0.9941 & 0.3049 \\
\hline
\end{tabular}


Table 6. $R^{2}$ and SE values for the polynomial regression models, female.

\begin{tabular}{ccccccc}
\hline \multirow{2}{*}{ States } & \multicolumn{2}{c}{ Model (2) } & \multicolumn{2}{c}{ Model (3) } & \multicolumn{2}{c}{ Model (4) } \\
\cline { 2 - 7 } & $\boldsymbol{R}^{2}$ & $\mathrm{~S}$ & $\boldsymbol{R}^{2}$ & $\mathrm{SE}$ & $\boldsymbol{R}^{2}$ & SE \\
\hline Andhra Pradesh & 0.8534 & 0.9856 & 0.8647 & 0.9802 & 0.8860 & 0.9717 \\
Assam & 0.9505 & 0.7291 & 0.9756 & 0.5302 & 0.9960 & 0.2316 \\
Bihar & 0.9446 & 0.7361 & 0.9909 & 0.3086 & 0.9974 & 0.1775 \\
Gujarat & 0.9158 & 0.5867 & 0.9912 & 0.1964 & 0.9922 & 0.2000 \\
Haryana & 0.6798 & 1.4004 & 0.9866 & 0.2970 & 0.9871 & 0.3141 \\
Himachal Pradesh & 0.8690 & 0.7491 & 0.8693 & 0.7743 & 0.9415 & 0.5597 \\
Karnataka & 0.8154 & 0.7382 & 0.9653 & 0.3314 & 0.9862 & 0.2257 \\
Kerala & 0.0739 & 1.1018 & 0.8186 & 0.4663 & 0.8692 & 0.4276 \\
Madhya Pradesh & 0.9623 & 0.6807 & 0.9952 & 0.2505 & 0.9971 & 0.2101 \\
Maharashtra & 0.9774 & 0.3797 & 0.9960 & 0.1657 & 0.9977 & 0.1346 \\
Odisha & 0.9932 & 0.2707 & 0.9940 & 0.2620 & 0.9956 & 0.2420 \\
Punjab & 0.9130 & 0.6987 & 0.9134 & 0.7215 & 0.9976 & 0.1310 \\
Rajasthan & 0.9298 & 0.6779 & 0.9944 & 0.1976 & 0.9970 & 0.1578 \\
Tamil Nadu & 0.8992 & 0.8952 & 0.9074 & 0.8883 & 0.9088 & 0.9520 \\
Uttar Pradesh & 0.8995 & 0.8905 & 0.9918 & 0.2634 & 0.9974 & 0.1598 \\
West Bengal & 0.9720 & 0.3959 & 0.9900 & 0.2444 & 0.9933 & 0.2158 \\
India & 0.9751 & 0.4284 & 0.9964 & 0.1679 & 0.9978 & 0.1413 \\
\hline
\end{tabular}

Table 7. Estimated life expectancy at birth $\left(e_{0}\right)$ for districts levels of Assam state.

\begin{tabular}{ccccc}
\hline & \multicolumn{2}{c}{$e_{0}$ by Model (2) } & \multicolumn{2}{c}{$e_{0}$ by Model (3) } \\
\cline { 2 - 5 } Districts & 2001 Census & 2011 Census & 2001 Census & 2011 Census \\
\hline Kokrajhar & 58.23 & 60.31 & 58.01 & 60.78 \\
Dhubri & 53.32 & 58.10 & 53.29 & 57.71 \\
Goalpara & 55.69 & 60.03 & 55.81 & 60.22 \\
Bongaigaon & 56.05 & 61.37 & 56.03 & 61.94 \\
Barpeta & 58.11 & 60.11 & 57.02 & 60.54 \\
Kamrup & 61.01 & 62.75 & 60.74 & 62.36 \\
Darrang & 54.32 & 59.72 & 54.12 & 58.97 \\
Marigaon & 57.01 & 59.17 & 57.08 & 58.8 \\
Nagaon & 57.11 & 60.42 & 57.32 & 60.62 \\
Sonitpur & 58.32 & 60.04 & 58.36 & 59.79 \\
Lakhimpur & 60.78 & 62.59 & 60.27 & 62.58 \\
Dhemaji & 60.28 & 63.01 & 60.72 & 62.98 \\
Tinsukia & 63.17 & 64.24 & 63.77 & 64.23 \\
Dibrugarh & 65.59 & 67.45 & 65.48 & 67.49 \\
Sivasagar & 60.67 & 63.36 & 60.05 & 63.04 \\
Jorhat & 62.65 & 64.16 & 62.24 & 64.41 \\
Golaghat & 62.54 & 62.10 & 62.12 & 62.74 \\
Karbi Anglong & 57.08 & 59.09 & 56.87 & 58.82 \\
North Cachar Hills & 60.01 & NA & 59.3 & NA \\
Cachar & 57.04 & 62.36 & 56.83 & 62.23 \\
Karimganj & 55.05 & 59.14 & 54.76 & 59.02 \\
Hailakandi & 56.79 & 58.32 & 56.77 & 57.66 \\
Dima Hasao & NA & 63.01 & NA & 62.82 \\
Chirang & NA & 61.02 & NA & 61.55 \\
Kamrup Metro & NA & 64.18 & NA & 64.68 \\
Baksa & NA & 62.52 & NA & 62.11 \\
Udalguri & NA & 61.17 & NA & 60.6 \\
\hline & & & &
\end{tabular}


Table 8. Estimated life expectancy at birth $\left(e_{0}\right)$ for 16 major Indian states and India, of 2001-05 and 2011-15.

\begin{tabular}{lcccccccc}
\hline & \multicolumn{3}{c}{ Life Expectancy at birth (2001-05) } & \multicolumn{3}{c}{ Life Expectancy at birth (2011-15) } \\
\cline { 2 - 8 } & $\begin{array}{c}(2001- \\
\text { 05) }\end{array}$ & $\begin{array}{c}\text { Model } \\
\text { States }\end{array}$ & $\begin{array}{c}\text { Model } \\
(4)\end{array}$ & $\begin{array}{c}\text { Model } \\
(2)\end{array}$ & $\begin{array}{c}\text { (2011- } \\
\text { 15) SRS }\end{array}$ & $\begin{array}{c}\text { Model } \\
(3)\end{array}$ & $\begin{array}{c}\text { Model } \\
(4)\end{array}$ & $\begin{array}{c}\text { Model } \\
(2)\end{array}$ \\
\hline Andhra Pradesh & 65.00 & 64.46 & 64.83 & 63.96 & 69.05 & 68.93 & 69.15 & 68.97 \\
Assam & 59.28 & 58.77 & 59.36 & 58.14 & 64.76 & 64.54 & 64.59 & 64.44 \\
Bihar & 64.13 & 63.94 & 63.96 & 63.08 & 68.63 & 68.59 & 68.57 & 68.09 \\
Gujarat & 65.65 & 65.66 & 65.71 & 65.19 & 69.35 & 69.31 & 69.32 & 69.17 \\
Haryana & 66.51 & 66.49 & 66.47 & 65.71 & 69.12 & 68.99 & 68.94 & 68.96 \\
Himachal Pradesh & 69.24 & 69.18 & 69.16 & 69.16 & 71.98 & 71.34 & 71.54 & 71.08 \\
Karnataka & 66.00 & 65.72 & 65.81 & 65.32 & 69.22 & 69.35 & 69.32 & 69.06 \\
Kerala & 73.57 & 73.38 & 73.11 & 74.44 & 75.41 & 75.50 & 75.21 & 74.13 \\
Madhya Pradesh & 59.62 & 59.39 & 59.47 & 59.30 & 64.78 & 64.83 & 64.90 & 64.79 \\
Maharashtra & 67.83 & 67.70 & 67.66 & 67.49 & 72.12 & 72.04 & 72.16 & 71.92 \\
Odisha & 60.84 & 60.68 & 60.73 & 60.68 & 66.79 & 66.76 & 66.70 & 66.76 \\
Punjab & 68.89 & 67.97 & 68.85 & 67.98 & 72.44 & 72.29 & 71.89 & 72.32 \\
Rajasthan & 64.47 & 64.57 & 64.58 & 63.52 & 67.97 & 68.04 & 68.05 & 68.03 \\
Tamil Nadu & 67.16 & 67.01 & 67.25 & 66.75 & 71.16 & 71.06 & 71.06 & 70.79 \\
Uttar Pradesh & 60.74 & 60.74 & 60.60 & 60.03 & 64.64 & 64.65 & 64.58 & 64.36 \\
West Bengal & 67.12 & 67.06 & 67.04 & 66.76 & 70.48 & 70.47 & 70.48 & 70.13 \\
India & 64.20 & 64.13 & 63.69 & 64.14 & 68.40 & 68.41 & 68.18 & 68.40 \\
\hline
\end{tabular}

\section{Conclusion}

When a thorough investigation is done based on SRS-data of Assam of the specific period with the help of regression techniques, a number of models emerge which estimate life expectancies at ages $x$ better than some established facts or standard ones such as dependence $L E(x)$ on $L E B$ or on $L E(1)$. On the other hand, strong dependence of life expectancy at birth on early childhood survivorship functions has been shown both analytically and empirically as the two proposed polynomial regression models have done well in the particular data used in the paper. The nature of the dependence is shown by the structure of the equations. In developing countries like India, these polynomials may be useful for estimating $e_{0}$ even when indirect techniques are used together with these polynomials.

\section{References}

1. R. Ramakumar, Technical Demography, $1^{\text {st }}$ Edition (New Age International (P) Limited, New Delhi, 1986).

2. C. J. L. Murrary, B. D. Ferguson, A. D. Lopez, M. Guillot, J. A. Salomon, and O. Ahmed, Popul. Stud. 57, 165 (2003). http://dx.doi.org/10.1080/0032472032000097083

3. F. W. Notestein, I. B. Taeuber, A. J. Coale, D. Kirk, and L. K. Kiser, The Future Population of Europe and the Soviet Union: Population Projections 1940-1970, League of Nations, 332, Geneva (1944).

4. Age and Sex Patterns of Mortality: Model Life-Tables for Under-Developed Countries (United Nations, Dept. of Social Affairs, Population Branch, 1955). 
https://searchworks.stanford.edu/view/4694003

5. A. J. Coale, P. Demeny, and B. Vaughan, Regional Model Life Tables and Stable Populations. (Academic Press, New York and London, 1983). https://doi.org/10.1016/B978-0-12-177080$\underline{8.50011-1}$

6. R. Kesarwani, Ph.D. Thesis, International Institute for Population Sciences, Mumbai, India, 2016.

7. K. R. Gabriel and I. Ronen, Popul. Stud. 12, 164 (1985). https://doi.org/10.2307/2172188

8. U. P. Sinha and R. B. Gupta, Model Life Tables for India, International Institute for Population Sciences, Mumbai, India (1979).

9. K. M. Ponnapalli, Construction of Model Life Tables for India: using SRS based Abridged Life Tables. Poster presented at Population Association of America (PAA), Dallas, Texas, (2010).

10. V. C. Romo and S. Becker, Demographic Res. 24, 113 (2011). http://dx.doi.org/10.4054/DemRes.2011.24.4

11. S. Mitra, Ind. J. Statist. Series B 36, 306 (1974). https://www.jstor.org/stable/25051914

12. P. Mahapatra, An Overview of the Sample Registration System in India. Paper Presented at the Prince Mahidol Award Conference \& Global Health Information Forum, Bangkok, Thailand, (2010). https://unstats.un.org/unsd/vitalstatkb/Attachment476.aspx?AttachmentType=1

13. R. Sarma and L. Choudhury, Canad. Stud. In Popul. 41 (2014). https://doi.org/10.25336/P6MS5D https://journals.library.ualberta.ca/csp/index.php/csp/article/view/22170/16466

14. S. Ledermann, Nouvelles Tables-Type de Mortalite:travaux et Document (Paris Institut National d'Etudes Demographiques, 1969).

15. S. G. Roy, Janasamkhya 7, 21 (1989).

16. R. Sarma and L. Choudhury, J. Data Sci. 10, 563 (2012). http://www.jds-online.com/files/JDS1072.pdf

17. Indirect Techniques for Demographic Estimation (United Nations, New York, 1983). https://www.un.org/en/development/desa/population/publications/pdf/mortality/Manual X.pdf

18. M. K. Choe, Fitting the Age Pattern of Infant and Child Mortality with the Weibull Survival Distribution, Asian and Pacific Census Forum 7, 10 (1981). 